\title{
NEW PYRIDINE-3-SULFONATO TIN (IV), ANTIMONY (III) AND (V) HALO ADDUCTS AND COMPLEXES: SYNTHESIS AND INFRARED STUDY
}

\author{
AÏSSATOU GUEYE ${ }^{1}$, MOUHAMADOU BIRAME DIOP ${ }^{1 *}$, LIBASSE DIOP ${ }^{1}$ \\ ${ }^{1}$ Université Cheikh Anta Diop, Faculté des Sciences et Techniques, Département de \\ Chimie, Laboratoire de Chimie Minérale et Analytique, Dakar, Sénégal
}

\begin{abstract}
Six new tin (IV), antimony (III) and antimony (V) adducts and complexes have been synthesized. Discrete structures were suggested on the basis of infrared data. Within the structures, the anion behaves as a bidentate, monochelating and monodentate, monodentate and tri O-chelating ligand. The environments around metallic centres are octahedral. Considering preamble of extra hydrogen bonds in compounds containing water molecules and/or $\mathrm{OH}$ groups, supramolecular architectures may be given rise.
\end{abstract}

Keywords: bidentate, monochelating and monodentate, monodentate and tri O-chelating ligand anion, discrete structures, octahedral tin and antimony centres, supramolecular architectures

\section{INTRODUCTION}

Organic and inorganic oxyanions behaving as ligand coordinated to various metallic centres are well known. Pyridine-3-sulfonate anion has not been studied as anion in the coordinating ability of oxyanions summarized by Hathaway [1]. Several worldwide groups among them our own, focused in this field through isolation and characterization of numerous compounds with oxyanions as ligands [2-6]. In the work reported herein, we have initiated the study of the interactions between $\mathrm{PySO}_{3} \mathrm{NMe}_{4}$ and $\mathrm{SnCl}_{2} 2 \mathrm{H}_{2} \mathrm{O}, \mathrm{SnBr}_{2}, \mathrm{SbCl}_{3}$ or $\mathrm{SbCl}_{5}$ : this enabled to isolate and characterize by infrared six new pyridine-3-sulfonate adducts and complexes.

\section{EXPERIMENTAL SETUP}

Neutralization of a tetramethylammonium hydroxide $\left(\mathrm{Me}_{4} \mathrm{NOH}\right)$ solution $\left(20\right.$ wt. \% in $\left.\mathrm{H}_{2} \mathrm{O}\right)$ with pyridine-3sulfonic acid $\left(\mathrm{PySO}_{3} \mathrm{H}\right)$ allowed to obtain tetramethyl ammonium pyridine-3-sulfonate, $\mathrm{Me}_{4} \mathrm{NPySO}_{3}(\mathbf{L})$ as a white powder collected after a forced water evaporation at $60^{\circ} \mathrm{C}$. The analytical data [\% calculated ( $\%$ found): $\% \mathrm{C}=46.53(46.45), \% \mathrm{H}=6.94(6.91), \% \mathrm{~N}=12.06(11.98), \% \mathrm{~S}=13.80(13.84)]$ have allowed to suggest the

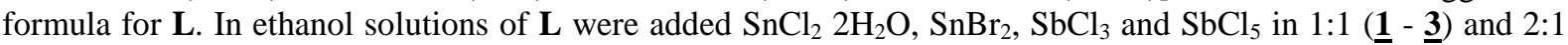
(4 - ) ratio, respectively. A white precipitate is quickly obtained then stirred around 2 hours and filtered off.

The analytical data reported below have allowed to suggest the formulae of the complexes and adducts (Table 1).

Chemicals were purchased from Aldrich Company (Germany) and used without any further purification. The elemental analyses are performed from the CNRS "Service Central d'Analyses" - Vernaison-France. IR spectra

\footnotetext{
* Corresponding author, email: mouhamadoubdiop@gmail.com

(c) 2019 Alma Mater Publishing House
} 
were recorded at the University of Padova (Italy) using a PE 580 spectrometer with CsI pellets, the sample being as Nujol mulls. IR abbreviations: vs(very strong), s(strong), m(medium).

Table 1. Results of the elemental analyses of compounds $1-6$.

\begin{tabular}{|c|c|c|c|c|c|c|c|c|c|}
\hline \multirow{3}{*}{ 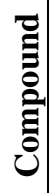 } & \multirow{3}{*}{ Suggested formulae } & \multicolumn{8}{|c|}{ Chemical composition [\% mass] } \\
\hline & & \multicolumn{2}{|c|}{$\mathbf{C}$} & \multicolumn{2}{|c|}{$\mathbf{H}$} & \multicolumn{2}{|c|}{$\mathbf{N}$} & \multicolumn{2}{|c|}{$\mathrm{Cl}$ or $\mathrm{Br}$} \\
\hline & & Calc. & Found & Calc. & Found & Calc. & Found & Calc. & Found \\
\hline$\underline{1}$ & $\mathrm{SbCl}_{5} \mathrm{Me}_{4} \mathrm{NPySO}_{3}$ & 20.34 & 20.42 & 3.04 & 3.12 & 5.27 & 5.34 & 33.36 & 33.51 \\
\hline$\underline{\underline{2}}$ & $\mathrm{SbCl}_{3} \mathrm{Me}_{4} \mathrm{NPySO}_{3}$ & 23.48 & 23.41 & 3.50 & 3.67 & 6.08 & 6.13 & 23.10 & 23.05 \\
\hline$\underline{\mathbf{3}}$ & $\mathrm{SnCl}_{4} \mathrm{Me}_{4} \mathrm{NPySO}_{3}$ & 21.93 & 21.94 & 3.27 & 3.27 & 5.68 & 5.64 & 28.78 & 28.85 \\
\hline$\underline{4}$ & $\mathrm{SnBr}_{5} \mathrm{NMe}_{4} \mathrm{Me}_{4} \mathrm{NPySO}_{3} \mathrm{EtOH} \mathrm{H}_{2} \mathrm{O}$ & 20.27 & 20.34 & 4.08 & 4.14 & 4.73 & 4.83 & 44.95 & 44.83 \\
\hline$\underline{\overline{5}}$ & $2 \mathrm{SnCl}_{3} \mathrm{OH} \mathrm{Me}_{4} \mathrm{NPySO}_{3} 2_{2} \mathrm{H}_{2} \mathrm{O} / 4 \mathrm{Me}_{4} \mathrm{NCl}$ & 15.40 & 15.48 & 3.23 & 3.29 & 4.04 & 4.01 & 28.41 & 28.44 \\
\hline$\underline{6}$ & $2 \mathrm{SnCl}_{2}(\mathrm{OH})_{2} \mathrm{Me}_{4} \mathrm{NPySO}_{3} \mathrm{Me}_{4} \mathrm{NCl}$ & 19.79 & 19.83 & 4.09 & 3.97 & 5.32 & 5.44 & 22.46 & 22.50 \\
\hline
\end{tabular}

\section{RESULTS AND DISCUSSION}

Let us consider the main IR data (in $\mathrm{cm}^{-1}$ ) of the six studied adducts and complexes:

1: vSb-Cl 330(vs), vSb-O or vSb-N 245(s);

2: vSb-Cl 275(s), vSb-O or vSb-N 240(vs);

3: vSn-Cl 325(vs), vSn-O or vSn-N 250(vs);

4: vSn-Br 210(vs), vSn-O or vSn-N 190(vs);

5: vSn-Cl 290(vs), vSn-O or vSn-N 215(m);

6: vSn-Cl 295(vs), vSn-O or vSn-N 235(s).

While considering the complex-anion $\left[\mathrm{PySO}_{3} \mathrm{SbCl}_{5}\right]^{-}$, within the suggested discrete structure of $\underline{\mathbf{1}}, \mathrm{Me}_{4} \mathrm{NPySO}_{3}$ $\mathrm{SbCl}_{5}$, reported on Figure 1, the pyridine-3-sulfonate ligand behaves as a N-donor (even we cannot exclude the O-coordination).

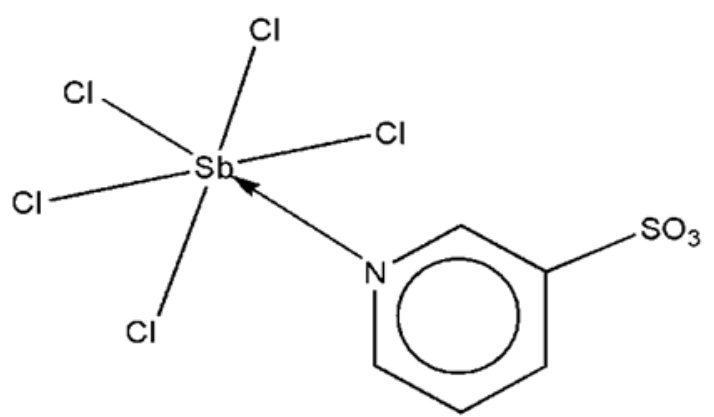

Fig. 1. Proposed structure for the compound 1.

For $\underline{2}, \mathrm{Me}_{4} \mathrm{NPySO}_{3} \mathrm{SbCl}_{3}$, we have considered the complex-anion $\left[\mathrm{PySO}_{3} \mathrm{SbCl}_{3}\right]^{-}$. The suggested structure is discrete reported on Figure 2 with a tri O-chelating ligand. These monomers may interact through $\mathrm{N}-\mathrm{Sb}$ dative bonds leading to an infinite chain.

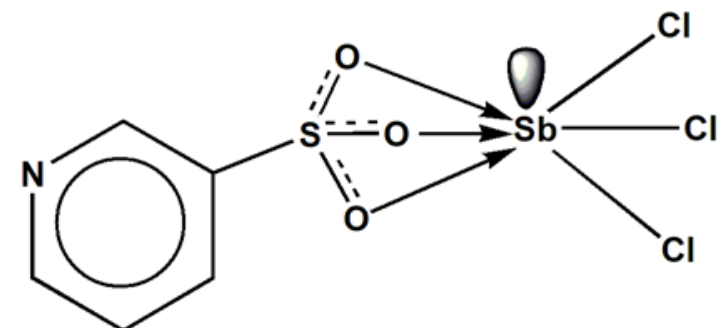

Fig. 2. Proposed structures for the compound 2. 
While considering the tin compounds, an oxidation of tin occurs in situ during the synthesis process [7]. $v_{\text {as }}\left(\mathrm{SnCl}_{4}\right)$ appears in the IR spectrum of $\underline{\mathbf{3}}$ as a very strong and sharp band (Eu type) indicating a transcoordination according to Groups Theory. So, considering the anion $\left[\mathrm{PySO}_{3} \mathrm{SnCl}_{4}\right]^{-}$an infinite chain, in which the pyridine-3-sulfonate anion behaves as a bridging bidentate $\mathrm{O}$ and $\mathrm{N}$-donors (Figure 3), can be proposed.

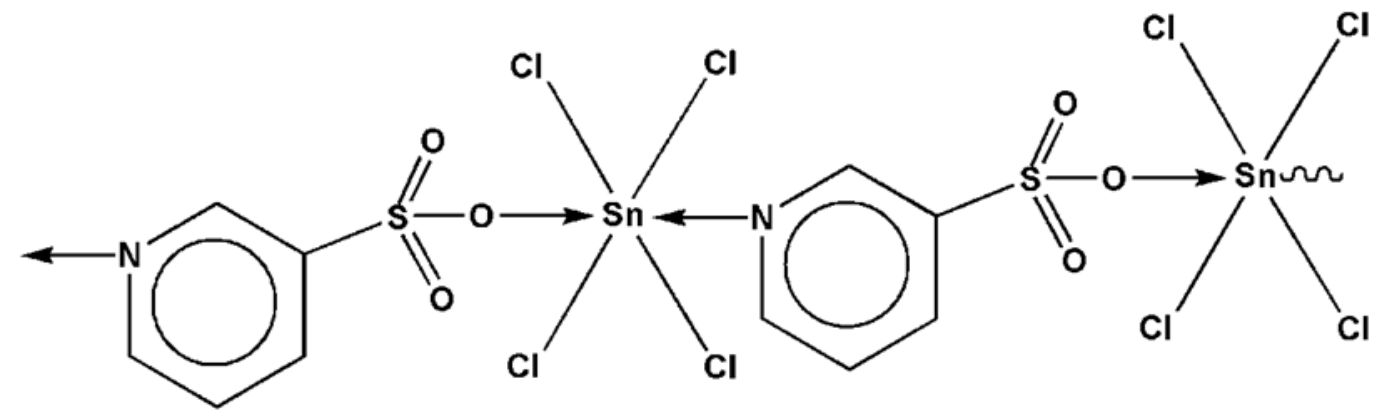

Fig. 3. Proposed structure for the compound 3.

The water and ethanol molecules as well as the anion may be considered coordinated to $\left[\mathrm{SnBr}_{5}\right]^{-}$in compound $\underline{\mathbf{4}}$. We arbitrary chosen the oxyanion coordinated to $\left[\mathrm{SnBr}_{5}\right]^{-}$leading to the discrete structure reported on Figure 4 , the water and ethanol molecules being lattice or linked to the complex-anion through hydrogen bonds leading a supramolecular arrangement.

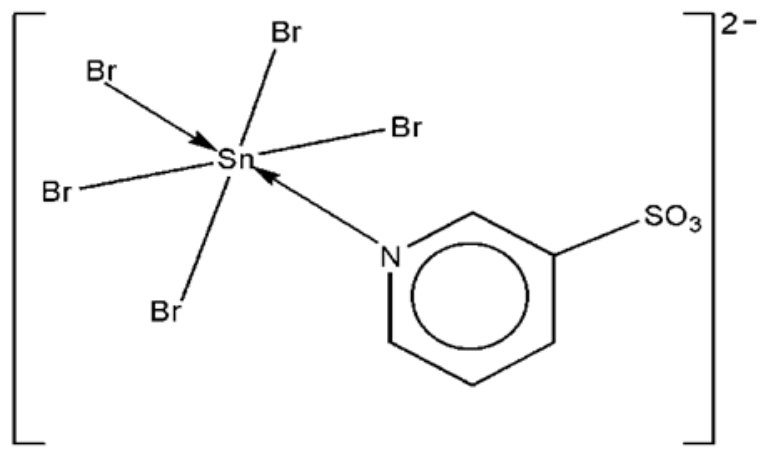

Fig. 4. Proposed structure for the compound 4.

For the complex-anion, $\left[\mathrm{PySO}_{3}\left(\mathrm{SnCl}_{3} \mathrm{OH}\right)_{2} 2 \mathrm{H}_{2} \mathrm{O}\right]^{-}$of $\underline{\mathbf{5}}$, considering the water molecules coordinated, the suggested structure is discrete and contains two $\mathrm{SnCl}_{3} \mathrm{OH} \mathrm{H} \mathrm{H}_{2} \mathrm{O}$ adducts [8] linked to $O$ and $N$ atoms rather than to two $\mathrm{O}$ atoms because of presumable strong steric effects (Figure 5).

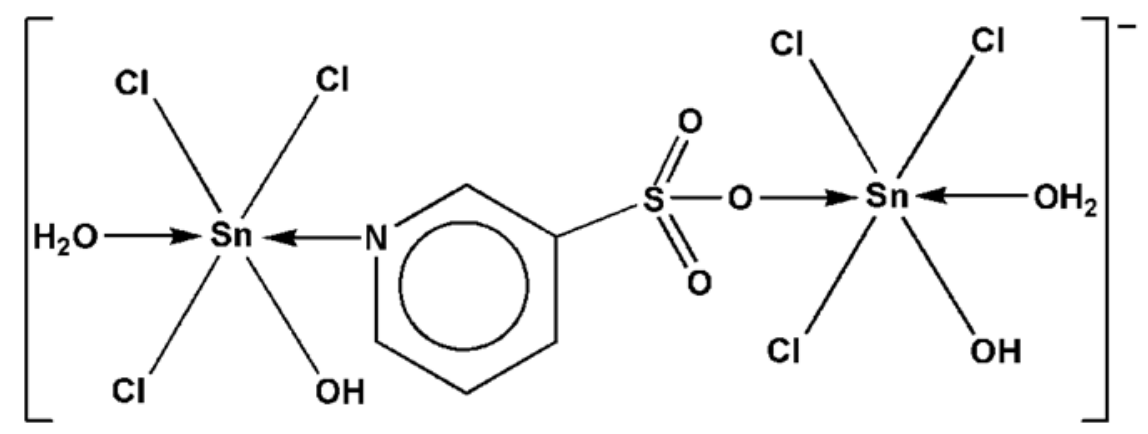

Fig. 5. Proposed structure for the compound 5.

For $\left[\left(\mathrm{PySO}_{3}\right) \mathrm{SnCl}_{2}(\mathrm{OH})_{2} \mathrm{Cl}\right]^{2-}$ complex-anion, the suggested structures are discrete. In the first, a chloride and a pyridine-3-sulfonate anion bridge two $\mathrm{SnCl}_{2}(\mathrm{OH})_{2}$ molecules (Figure 6a). The second structure is dimeric and 
centrosymmetric comprising two chlorides bridging two molecules of $\mathrm{SnCl}_{2}(\mathrm{OH})_{2}$ and two pyridine-3-sulfonate anions which bridge the former bridged molecules (Figure $6 \mathrm{~b}$ ).

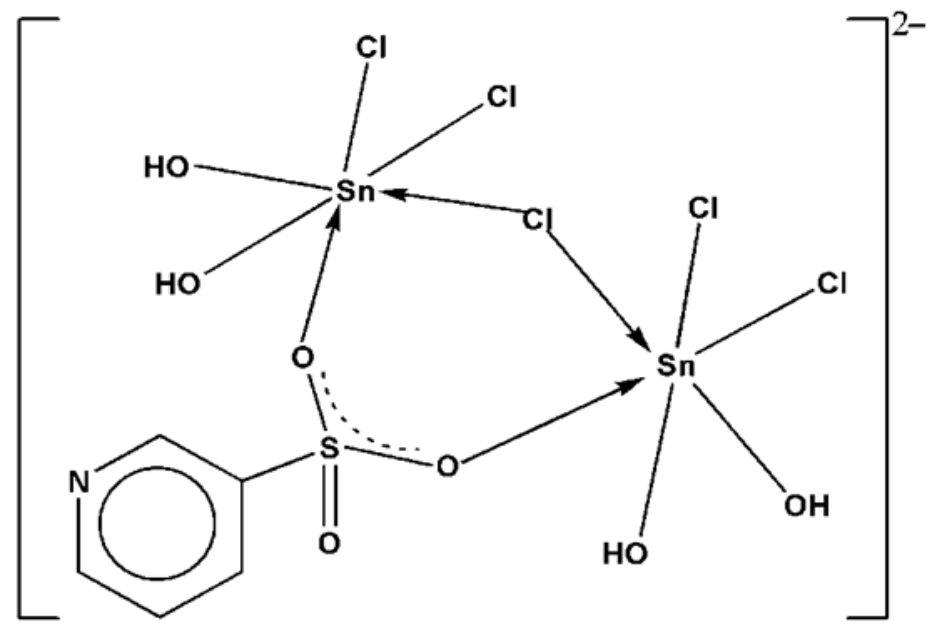

a)

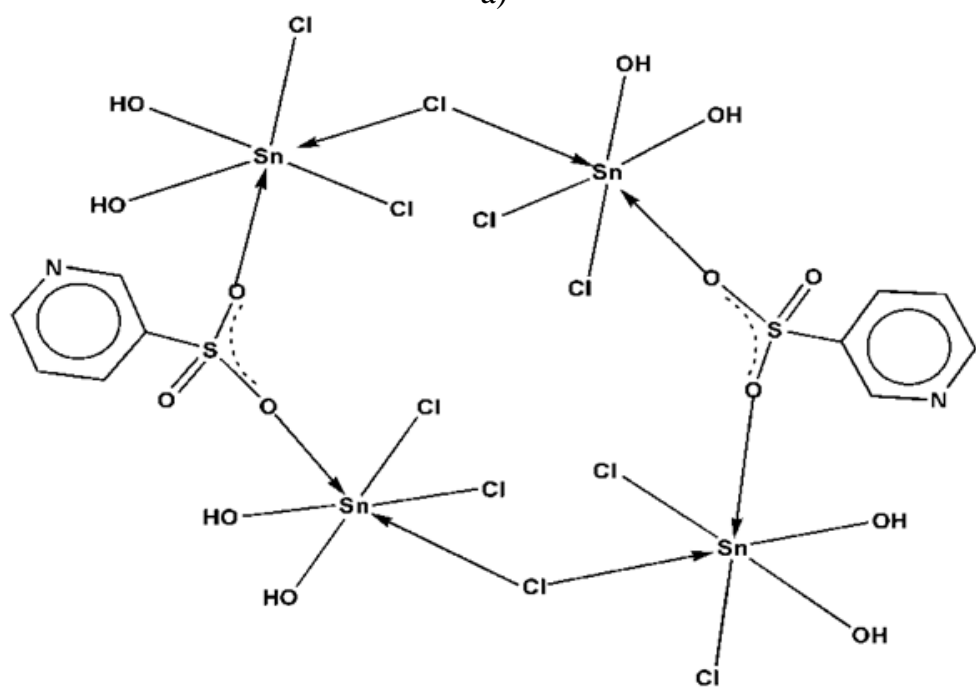

b)

Fig. 6. Proposed structures for the compound 6.

In all compounds, the anion can interact through $N$ or $O$; it appears very difficult from the infrared data to choose between these two possible behaviours.

In all these structures, the tetramethyl ammonium ion interacts electrostatically with the complex-anion. Hydrogen bonds may be considered in $\mathrm{OH}$ and water containing structures leading to supramolecular arrangements.

\section{CONCLUSIONS}

Along this study, the suggested structures are discrete or of infinite chain. Pyridine-3-sulfonate anion behaves as a bridging bidentate, $\mathrm{N}$-donor and tri O-chelating. The environments around the tin( IV) and $\mathrm{Sb}$ centres are both octahedral. The possible inter species hydrogen bonds may give rise to supramolecular architectures.

\section{ACKNOWLEDGEMENTS}

We thank Professor M.Vidali (Padova University-Italy) for equipment support. 


\section{REFERENCES}

[1] Hathaway, B.J., Comprehensive coordination chemistry (Editors: Wilkinson, G., Gillard, R.D., McCleverty, J.A.), 1st ed., Chapter 53, Pergamon Press, Oxford, vol. 5, 1987, p. 413.

[2] Diop, T., Diop, L., Michaud, F., Ardisson, J.D., Et ${ }_{4} \mathrm{~N}\left[\mathrm{NO}_{3}\left(\mathrm{SnClPh}_{3}\right)_{2}\left(\mathrm{SnPh}_{3} \mathrm{NO}_{3}\right)\right]$ : a trinuclear organostannate complex and related derivatives, Main Group Metal Chemistry, vol. 36, 2013, p. 83-88.

[3] McCann, M., Curran, R., Ben-Shoshan, M., McKee, V., Devereux, M., Kavanagh K., Kellett, A., Synthesis, structure and biological activity of silver(I) complexes of substituted imidazoles, Polyhedron, vol. 56, 2013, p. 180-188.

[4] Reddy, J.P., Foxman, B. M., Crystal and molecular structure of a second, high-density polymorph of silver malonate, Journal of Molecular Structure, vol. 890, 2008, p. 227-231.

[5] Fu, J., Zheng, L., Yuan, Y., Song, Y., Xu, Y., Hydrothermal synthesis, crystal structure and properties of two organic amine templated lanthanide sulfates, Journal of Chemical Crystallography, vol. 41, 2011, p. $1737-1741$.

[6] Li, C.P., Nie, L., Pei, W.B., Li, L., Tian, Z.F., Liu, J.L., Gao, X.S., Ren, X.M., Magnetic feature and nearinfrared absorption of a $\left[\mathrm{Pt}(\mathrm{mnt})_{2}\right]^{-}$-based H-bond supramolecular crystal, Journal of Solid State Chemistry, vol. 243, 2016, p. 38-43.

[7] Sarr, M., Diallo, W., Diasse-Sarr, A., Plasseraud, L., Cattey, H., Tris(cyclohexylammonium) cisdichloridobis(oxalato- $\kappa^{2} O^{1}, O^{2}$ ) stannate (IV) chloride monohydrate, Acta Crystallographica, vol. E69, 2013, p. m581-m582.

[8] Diop, M.B., Diop, L., Plasseraud, L., Maris, T., Crystal structure of 2-methyl-1H-imidazol-3iumaquatrichlrido(oxalate- $\kappa^{2} \mathrm{O}, \mathrm{O}^{\prime}$ ) stannate (IV), Acta Crystallographica, vol. E71, 2015, p. 520-522. 